\section{Letter to the Editor-A Preliminary Investigation of Siblicide as a Function of Genetic Relatedness}

Sir:

Siblicide - the killing of one sibling by another-is rare relative to other types of homicide. Underwood and Patch (1) reported that of 65,390 homicides coded in the Supplementary Homicide Reports (SHRs) of the Federal Bureau of Investigation (FBI) for the years 1993 through 1995, only $572(0.9 \%)$ were cases in which the offender and victim were siblings. Even if including only intrafamilial homicides, siblicide is infrequent, with just 996 of 13,105 (7.6\%) coded as sibling homicides in the Uniform Crime Reports of the FBI for the years 1992 through 1996 (1). Although siblicide is rare relative to other homicides, violence between siblings is the most frequent form of intrafamilial nonlethal violence (2-4). The study of siblicide may provide a window into sibling relationships and nonlethal sibling conflict.

An evolutionary perspective has been applied profitably to the study of homicide $(5,6)$, and to siblicide in particular $(7,8)$. Research generated by an evolutionary perspective suggests that predictable differences may exist in the contexts and circumstances of siblicides of full siblings, half-siblings, and stepsiblings. This is because genetic relatedness may be an important moderator of conflict in family relationships, including sibling relationships $(6,7,9)$.

As Gebo (10) notes, research on siblicide has not differentiated siblings according to genetic relatedness. There may be reasons to make such a differentiation, however. Siblings may be less likely to kill a full sibling, for example, because the evolutionary "fitness" costs associated with the death of a full sibling (with whom the perpetrator shares $50 \%$ of his or her genes) are higher than the fitness costs associated with the death of a half-sibling or a stepsibling (with whom the perpetrator shares just $25 \%$ or $0 \%$ of his or her genes, respectively). In addition, the psychological processes involved might be different for siblicides of half-siblings and stepsiblings, relative to siblicides of full siblings. For example, siblicides of half-siblings and stepsiblings may be more likely than those of full siblings to produce more than one victim, because half-siblings and stepsiblings may be more likely to commit siblicide during a moment of intense bitterness and resentmentemotions that may co-occur with greater behavioral disorganization and spontaneity $(11,12)$. Full siblings, on the other hand, may select and murder their victims more deliberately, singling out one particular sibling - perhaps that sibling perceived by the perpetrator as receiving a greater share of parental investment $(6,7)$. The siblicide in this case may be premeditated, with full siblings choosing a time and a place when no others are around, for example. We offer the following prediction as a preliminary test of this logic (and see (11), for parallel arguments and empirical support in the context of filicide-suicide):

Prediction 1: A greater proportion of siblicides of full siblings will be single-victim siblicides, relative to the proportion of siblicides of half-siblings and stepsiblings.

Stepparents more frequently use a more brutal method of killing their wards than do genetic parents, arguably revealing feelings of bitterness and resentment in stepparents not present to the same degree in genetic parents $(12,13)$. In this study, we define "beating" as a relatively brutal killing method that includes the use of a blunt instrument or the use of one's hands, fists, or feet, following
Daly and Wilson ((13); and see (12)). Parental investment in halfsiblings or stepsiblings may be viewed by a sibling as "wasted" investment, relative to investment in full siblings (who share more genes with the sibling). This "misdirected" investment may lead to feelings of bitterness and resentment toward half-siblings and stepsiblings that are not present to the same degree toward full siblings. Following this logic, we offer the following prediction (and see (12) and (13), for parallel arguments and empirical support):

Prediction 2: A greater proportion of siblicides of half-siblings and stepsiblings will be perpetrated by beatings, relative to the proportion of siblicides of full siblings.

We used a city-wide homicide database covering a 30-year period to test these predictions.

The Chicago Homicide Database (CHD) provides incidentlevel information on 22,988 homicides recorded in the murder analysis files of the Chicago Police Department for the years 1965-1994 (14). The CHD is the largest database known to the authors that codes for the genetic relationship between the siblicide victim and the offender. We selected for analysis the 232 cases in which one sibling killed another sibling. Two hundred and sixteen of these siblicides were committed by full siblings. Sixteen siblicides were committed by half-siblings or stepsiblings (nine by half-siblings, seven by stepsiblings). The overwhelming majority of siblicide offenders and victims were male $(81.0 \%$ and $82.3 \%$, respectively) and between the ages of 15 and 44 years (85.3\% and $80.6 \%$, respectively). Following Daly and Wilson (13) and Weekes-Shackelford and Shackelford (12), we combined the weapon variable coded as "club or blunt instrument" with the weapon variable coded as "hands, fists, or feet" to form the category "beating."

Prediction 1 stated that a greater proportion of siblicides of full siblings will be single-victim siblicides, relative to the proportion of siblicides of half-siblings and stepsiblings. Full siblings killed a single victim in 209 (96.8\%) cases. Half-siblings and stepsiblings, in contrast, killed a single victim in $14(87.5 \%)$ cases. This difference was in the predicted direction but did not reach statistical significance $(z=1.04, p>0.05)$. Prediction 2 stated that a greater proportion of siblicides of half-siblings and stepsiblings will be perpetrated by beatings, relative to the proportion of siblicides of full siblings. Two (12.5\%) of the siblicides committed by halfsiblings and stepsiblings were coded as beatings, compared with $13(6.0 \%)$ of the siblicides committed by full siblings. As for the test of Prediction 1, this difference was in the predicted direction but did not reach statistical significance $(z=0.27, p>0.05)$.

Guided by an evolutionary perspective, we tested two predictions about siblicides committed by full siblings, half-siblings, and stepsiblings. The first prediction stated that a greater proportion of siblicides of full siblings will be single-victim siblicides, relative to the proportion of siblicides of half-siblings and stepsiblings. The second prediction stated that a greater proportion of siblicides of half-siblings and stepsiblings will be perpetrated by beatings, relative to the proportion of siblicides of full siblings. The results are in the predicted direction for both predictions, but neither result reached statistical significance. This failure to reach statistical significance may be attributable to small sample size and, therefore, to inadequate statistical power (15). The current research is notable, nonetheless, because it is the first investigation of siblicide as a function of the genetic relatedness between the victim and offender. 
A clear problem of tests of the current predictions is the lack of a large, national-level homicide database that codes for the genetic relationship between the siblicide victim and the offender. In the absence of such a database, analyses comparing full siblings to half-siblings and stepsiblings are limited to smaller databases that do have such codes. The CHD does code for this relationship, but is not without limitations. One limitation of the CHD is that it does not code for the relationship of multiple victims to a single offender. Without this information, we are not able to assess whether multiple-victim homicides were perpetrated against additional siblings, other relatives, or strangers (see also (7)).

This study used a database of nearly 23,000 homicides committed in Chicago during the years 1965-1994 to test predictions about the contexts and circumstances of siblicide. Even in this city-level database covering nearly 30 years, few siblicides were committed, rendering it impossible to perform statistically powerful tests of the predictions. The results might nevertheless be interpreted as providing preliminary qualitative evidence of the potential value of differentiating genetic relationships in siblicide research (see (16), for a recent argument regarding the value of small-sample, qualitative research). What is needed is a much larger siblicide database that codes for the genetic relationship between the victim and offender. We are not aware of any such database, but offer that it may be feasible and relatively simple to add such a code to existing national-level databases, including, for example, the SHRs of the FBI.

\section{References}

1. Underwood RC, Patch PC. Siblicide: a descriptive analysis of sibling homicide. Homicide Stud 1999;3:333-48.

2. Gelles R, Straus M. Intimate violence. New York: Simon \& Schuster, 1988.

3. Wallace H. Family violence. Boston: Allyn \& Bacon, 1996.

4. Wiehe VR. Sibling abuse. Thousand Oaks, CA: Sage Publications, 1997.
5. Buss DM. Evolutionary psychology. 2nd ed. Boston: Allyn \& Bacon, 2004.

6. Daly M, Wilson M. Homicide. Hawthorne, NY: Aldine de Gruyter, 1988.

7. Daly M, Wilson M, Salmon CA, Hiraiwa-Hasegawa M, Hasegawa T. Siblicide and seniority. Homicide Studies 2001;5:30-45.

8. Sulloway FJ. Born to rebel. New York: Pantheon, 1996.

9. Daly M, Wilson M. The truth about Cinderella. London: Weidenfeld \& Nicolson, 1998

10. Gebo E. A contextual exploration of siblicide. Violence Victims 2002;17:157-68.

11. Shackelford TK, Weekes-Shackelford VA, Beasley SL. An exploratory analysis of the contexts and circumstances of filicide-suicide in Chicago, 1965-1994. Aggressive Behav 2005;31:399-406.

12. Weekes-Shackelford VA, Shackelford TK. Methods of filicide: stepparents and genetic parents kill differently. Violence Victims 2004;19:75-81.

13. Daly M, Wilson MI. Some differential attributes of lethal assaults on small children by stepfathers versus genetic fathers. Ethol Sociobiol 1994;15:207-17.

14. Block CR, Block RL. Homicides in Chicago, 1965-1995 [Computer file]. Third ICPSR version. Chicago: IL. Criminal Justice Information Authority [producer]. Ann Arbor, MI: Inter-university Consortium for Political and Social Research [distributor], 1997.

15. Cohen J. Statistical power analysis for the behavioral sciences. 2nd ed. Hillsdale, NJ: Lawrence Erlbaum Associates, 1988.

16. Farr KA. Battered women who were "being killed and survived it": straight talk from survivors. Violence Victims 2002;17:267-81.

Daniel P. Russell, B.A., Todd K. Shackelford, Ph.D., and Viviana A. Weekes-Shackelford, M.A. Department of Psychology

Florida Atlantic University

2912 College Avenue

Davie, FL 33314

Richard L. Michalski, Ph.D

Department of Psychology

Hollins University

Roanoke, VA 24020 